\title{
Effect of Fillet Geometry to Joint Strength of Four-Pipe-Brazed Specimen for Rocket Nozzle Skirt*
}

\author{
Toshi-Taka IKESHOJI**, Akio SUZUMURA** and Takahisa YAMAZAKI**
}

\begin{abstract}
The strength of the brazed joint of the four-pipe-brazed specimen (4PB), which imitates the rocket nozzle skirt's wall, is analyzed numerically. The 4PB specimen comprises four pipes brazed side by side with JIS BPd-6 palladium brazing filler metal. The effect of the fillet geometry to the joint strength of the $4 \mathrm{~PB}$ specimen is investigated. The numerical analysis is conducted for the $4 \mathrm{~PB}$ of $10 \mathrm{~mm}$ diameter with various root gaps from 0.05 to $3.0 \mathrm{~mm}$ and various apparent fillet widths from 1.0 to $4.0 \mathrm{~mm}$. The nominal rupture strain is obtained by the comparison of von Mises' equivalent stress of the fillet and the pipes with their maximum tensile stress. The results show that the fracture of the 4PD specimens always occurs at the fillet. The nominal rupture strain tends to have weak correlation with the root gap, but in positive proportion to the apparent fillet width.
\end{abstract}

Key Words: Palladium Brazing Filler Metal, Super Alloy, Elastic-Plastic Analysis, Finite Element Method

\section{Introduction}

The present large scale rocket engines are mostly using the mixture of liquid hydrogen and liquid oxygen as the propellants ${ }^{(1)}$. They feature the regenerative cooling nozzle skirt. The nozzle skirt is cooled by circulating the liquid hydrogen fuel directly in the nozzle skirt's wall in order to avoid the melting down of its inner wall exposed to the high temperature combustion gas flow. Simultaneously, the circulating system preheats the liquid hydrogen fuel to regenerate a part of the lost combustion gas energy, and the thrust efficiency of the rocket engine is improved.

The nozzle skirt assemblies (NSA) with the regenerative cooling system of the western countries have the pipe work structure ${ }^{(2),(3)}$. Their NSA's wall comprises the super alloy pipes, through which the fuel coolant is circulating. The pipes are joined by brazing in the cases of the Space Shuttle Main Engine (SSME) of the Boeing Company and the LE-7A rocket engine of the Mitsubishi Heavy Industry. The LE-7A's NSA comprises 350 pipes of JIS SUH660 or ASTM SS66286 heat resisting steel. They are brazed side by side using the JIS BPd-6 palladium brazing filler metal.

The quality control of the LE-7A's NSA is conducted

* Received 30th May, 2005 (No. 05-4140)

** Mechanical \& Aerospace Systems Engineering, Tokyo Institute of Technology, 2-12-1-I1-32 O-okayama, Meguro-ku, Tokyo 152-8552, Japan.

E-mail: ikeshoji@mep.titech.ac.jp by the in-process inspection: before the brazing process, the root gap between the pipes and the apparent width of the fillet are checked to be under a certain width, and after the brazing, the surface of the fillet is observed. If necessary, the inside of the fillet is probed by the ultrasonic flaw detection. The geometrical criteria of this in-process inspection for the brazed fillet are, however, empirically configured. The goal of the present research is to provide the certified ground for those geometrical criteria for the brazing fillet to improve the quality assurance of the NSA's brazed joint.

The joint strength of the NSA's fillet is usually measured by the tensile fracture test for the so-called, fourpipe- brazed specimen $(4 \mathrm{~PB})^{(4)}$. The $4 \mathrm{~PB}$ comprises the 4 pieces of pipes (Fig. 1 (a)). They are brazed side by side using the same brazing filler metal of the NSA and in the same brazing conditions of the NSA's brazing process. In the hole of the middle 2 pipes, the resin is stuffed, and in the holes of outer 2 pipes, the rigid bars of same diameter with the inner diameter of the pipe are inserted to load the tensile load by pulling them in the opposite directions.

The tensile test for the 4PB might show the joint strength under the operating conditions of the rocket engine, if the conditions could be applied to the 4PB. Under the operating conditions, the 4PB pipes must be cooled from inner wall to low temperature of $80^{\circ} \mathrm{K}$ and pressured to $30 \mathrm{MPa}$, imitating the flow of liquid hydrogen. A side of its outer wall must be heated to $800^{\circ} \mathrm{K}$ on the assump- 


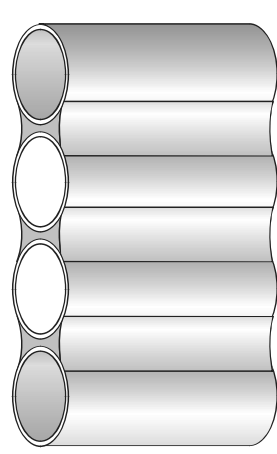

(a)

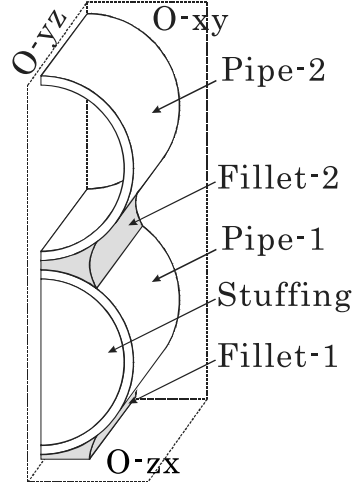

(b)
Fig. 1 Illustration of (a) the four-pipes-brazed specimens and (b) the model

tion of the combustion gas flow. But such the experimental tests under those conditions are severely difficult to accomplish. Therefore, the numerical simulation for the tensile tests of the $4 \mathrm{~PB}$ specimens are the expected method to obtained the fillet's property.

In the present research, it is investigated the relationship between those geometrical parameters of fillet and its joint strength using the finite element method with the elastic-plastic deformation analysis. The nominal strain to rupture is obtained in each geometric case. The rupture is decided by the comparison of material properties and calculated the von Mises' stress and strain.

\section{Nomenclature}

$C:$ Hardening coefficient $[\mathrm{GPa}]$

$E$ : Young modulus [GPa]

$g:$ Gap between the pipes [mm]

$h:$ Apparent fillet width [mm]

$m$ : Hardening exponent of Ramberg-Osgood model

$n$ : Hardening rate

$R:$ Radius of pipe [mm]

$\alpha$ : Yielding offset of Ramberg-Osgood model [MPa]

$\varepsilon:$ Strain [\%]

$\varepsilon_{\max }:$ Rupture strain [\%]

$\bar{\varepsilon}_{\text {max }}$ : Nominal rupture strain [\%]

$\varepsilon_{\mathrm{VM}}$ : von Mises' equivalent strain [\%]

$\varepsilon_{\mathrm{VM}, \max }$ : Max. von Mises' equivalent strain [\%]

$v:$ Poisson's ratio

$\bar{\rho}:$ Equivalent curvature $\left[\mathrm{mm}^{-1}\right]$

$\sigma:$ Stress [MPa]

$\sigma_{\max }:$ Max. stress [MPa]

$\sigma_{\mathrm{VM}}:$ von Mises' equivalent stress [MPa]

$\sigma_{\mathrm{VM}, \max }$ : Max. von Mises' equivalent strain [\%]

$\sigma_{\mathrm{Y}}:$ Yielding stress $[\mathrm{MPa}]$

\section{Numerical Calculation}

The object of the present numerical calculation was the 4 pipes brazed specimen (4PB) which comprises 4

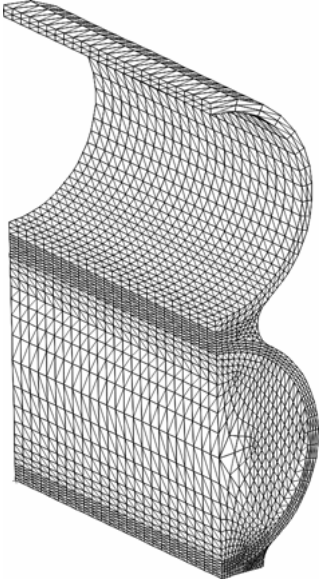

(a)

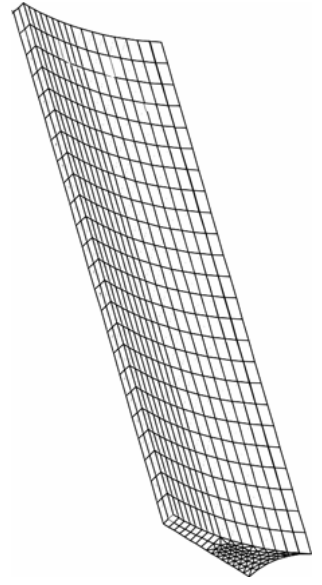

(b)
Fig. 2 Mesh for (a) the four-pipes-brazed specimen and (b) fillet-1

stainless steel pipes and 3 fillets (Fig. 1). The pipes were the austenitic stainless steel, JIS SUS304. The fillet was formed by the brazing filler metal of JIS BPd-6. It was reinforced by the nickel powder. In the hole of the middle 2 pipes, the Poly methyl methacrylate (PMMA) was stuffed. In the holes of the outer 2 pipes, the rigid bars with no deformation were inserted and adhered to the inner wall of the holes. For this 4PB specimen, the Instron type tensile fracture test was postulated. The tensile displacement of $0.10 \mathrm{~mm}$ was applied by displacing the separation of the rigid bars.

The $4 \mathrm{~PB}$ has the symmetry on the $O-x y,-y z$ and $z x$ planes. The calculated region was the one eighth of the 4PB model.

The radius of the pipe, $R$, was $5.0 \mathrm{~mm}$ and its wall thickness was $0.5 \mathrm{~mm}$. The length of the pipe in the calculated region was $14 \mathrm{~mm}$. The root gap between the pipes was given as $g \mathrm{~mm}$. The value of $g$ varies from $0.05 \mathrm{~mm}$ to $0.3 \mathrm{~mm}$.

The contour of the fillet is the arc touching to the outer surface of the pipes (Fig. 3). The separation of the touching points is the given as $h$, which varies from $1.0 \mathrm{~mm}$ to $4.0 \mathrm{~mm}$. Its arc radius, $r$, and the position of the fillet's arc center, $f$ are

$$
\begin{aligned}
& r=R h /(2 R+g-h) \\
& f=\sqrt{(R+r)^{2}-(R+g / 2)^{2}}
\end{aligned}
$$

Their values are tabulated in Table 2 .

For the finite element analysis, the model was separated by the continuum solid elements (Fig. 2). The 8node brick element was assigned to the pipes, fillets and stuffing. The 6-node wedge element was assigned to the outer part of the fillets. The fillet- 1 and the pipe- 1 were meshed finer than the fillet-2. The total number of nodes was 21150 and the total number of elements was 20568 .

The plane symmetry boundary conditions were ap- 


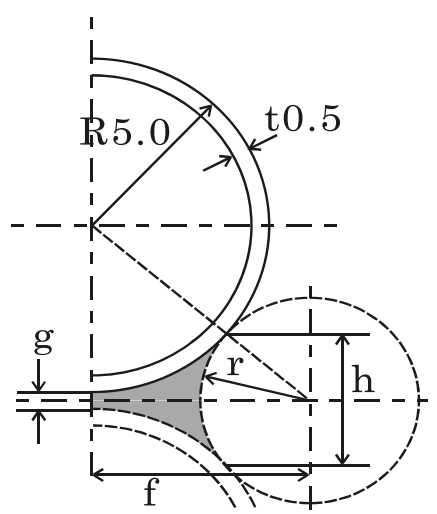

Fig. 3 Geometry of the fillet

Table 1 Mechanical properties

\begin{tabular}{|c|r|r|r|}
\hline Material & $\begin{array}{c}\text { BPd-6 }+ \\
\text { Ni } \\
\text { powder }\end{array}$ & SUS304 & PMMA \\
\hline$E[\mathrm{GPa}]$ & 130.0 & 195.8 & 3.102 \\
\hline$v$ & 0.378 & 0.25 & 0.33 \\
\hline$\sigma_{\mathrm{Y}}[\mathrm{MPa}]$ & 100.0 & 234.9 & 73.5 \\
\hline$\sigma_{\max }[\mathrm{MPa}]$ & 264.0 & 600.7 & $-\cdot$ \\
\hline$\varepsilon_{\max }[\%]$ & 14.6 & 48.2 & $(6.0)$ \\
\hline$n^{1)}$ & 0.188 & 0.223 & -- \\
\hline$m^{2)}$ & 4.760 & 4.498 & 5.13 \\
\hline$\alpha^{3)}$ & 0.971 & 0.969 & $-\cdot$ \\
\hline
\end{tabular}

(1) Hardening rate. (2) Hardening exponent and (3) Yielding offset of Ramberg-Osgood model.

Table 2 Dimensions of the fillets

\begin{tabular}{|l|l|l|l|l|}
\hline & $g$ & $h$ & $r$ & $f$ \\
\hline$\# 1$ & 0.05 & 1.00 & 0.552 & 2.362 \\
\hline$\# 2$ & 0.05 & 2.00 & 1.242 & 3.703 \\
\hline$\# 3$ & 0.05 & 3.00 & 2.128 & 5.055 \\
\hline$\# 4$ & 0.05 & 4.00 & 3.306 & 6.613 \\
\hline$\# 5$ & 0.10 & 1.00 & 0.549 & 2.301 \\
\hline$\# 6$ & 0.10 & 2.00 & 1.235 & 3.656 \\
\hline$\# 7$ & 0.10 & 3.00 & 2.113 & 5.009 \\
\hline$\# 8$ & 0.10 & 4.00 & 3.279 & 6.560 \\
\hline$\# 9$ & 0.20 & 1.00 & 0.543 & 2.173 \\
\hline$\# 10$ & 0.20 & 2.00 & 1.220 & 3.560 \\
\hline$\# 11$ & 0.20 & 3.00 & 2.083 & 4.916 \\
\hline$\# 12$ & 0.20 & 4.00 & 3.226 & 6.454 \\
\hline$\# 13$ & 0.30 & 1.00 & 0.538 & 2.035 \\
\hline$\# 14$ & 0.30 & 2.00 & 1.205 & 3.461 \\
\hline$\# 15$ & 0.30 & 3.00 & 2.055 & 4.822 \\
\hline$\# 16$ & 0.30 & 4.00 & 3.175 & 6.348 \\
\hline
\end{tabular}

Unit is in $\mathrm{mm}$.

plied on the $O-x y,-y z$ and $-z x$ planes. The displacement of the contour of the internal wall of pipe- 2 was confined to keep its cylindrical shape, and the $0.2 \mathrm{~mm}$ displacement in the $y$-direction was applied step by step in units of $0.02 \mathrm{~mm}$.

The mechanical properties of the materials are shown in Table $1^{(5)-(7)}$. The constitutive models for the fillet material and the stainless steel were the Ramberg-Osgood model $^{(8)}$, which allowed dealing the fully plastic analysis for the ductile materials;

$$
E \varepsilon=\sigma+\alpha\left(|\sigma| / \sigma_{Y}\right)^{m-1} \sigma
$$

The constitutive relation including the plastic deformation is commonly described in the form:

$$
\sigma=C \varepsilon^{n}
$$

The approximated values of the hardening rate, $m$, and the hardening exponent, $\alpha$, of the Ramberg-Osgood model were calculated by fitting the curve of Eq. (3) to the curve of Eq. (4) using the least square method. The mechanical properties, $C$ and $n$, of this powder reinforced brazing filler metal was experimentally obtained.

The PMMA stuffing was considered the rateindependent elastic-perfect plastic material.

For the model under the boundary conditions, the nonlinear static elastic-plastic analysis was conducted using the general purpose finite element analysis tool, ABAQUS.

\section{Results}

The results of the numerical calculations were evaluated only for the fillet- 1 and pipe- 1 , because the pipe- 2 was the part just to transmit the stress induced by the given displacement and the fillet- 2 was directly affected by the pipe-2.

For the case \#1 with the root gap of $0.05 \mathrm{~mm}$ and the apparent fillet width of $1.00 \mathrm{~mm}$, the contour of the von Mises' equivalent stress and strain in the fillet- 1 and pipe1 were shown in Fig. 4. In Fig. 4(a), the upper left part is the center part of the fillet and the lower right part is the outer surface. The maximum von Mises' equivalent stress, $\sigma_{\mathrm{VM}, \max }$, appeared on the touching edge of the fillet with the pipe's surface. The $\sigma_{\mathrm{VM}, \max }$ was $272.0 \mathrm{MPa}$ and near to the maximum stress of the BPd-6+Ni powder. In Fig. 4 (b), though the contour is indistinct, the point of $\sigma_{\mathrm{VM}, \max }$ was inside the wall near the touching line with the fillet. The $\sigma_{\mathrm{VM}, \max }$ value was larger than $300 \mathrm{MPa}$, but was still a half of the maximum stress of the SUS304 stainless steel. Around the touching edge, the pipe wall deformed to bend like the fringe, although the magnitude of the deformation was very small (Fig. 4(d)). The maximum von Mises' equivalent strain in the fillet- 1 also appeared at the touching edge. Unlike the $\sigma_{\mathrm{VM}, \max }$, the $\varepsilon_{\mathrm{VM}, \text { max }}$ was high on the outer side of the fillet.

For the other geometrical cases, the sites where the $\sigma_{\mathrm{VM}, \max }$ and $\varepsilon_{\mathrm{VM}, \text { max }}$ appeared were almost the same.

Figure 5 shows the changes of $\sigma_{\mathrm{VM}, \text { max }}$ and $\varepsilon_{\mathrm{VM} \text {, max }}$ in the fillet-1 and the pipe-1 with the nominal strain. The nominal strain is the ratio of the displacement at the upper tip point of the pipe- 2 and the initial height at the point. When the root gap and the apparent fillet width were minimum in the present calculation, i.e. $r=0.05 \mathrm{~mm}$ and $h=1.00 \mathrm{~mm}$ (case \#1), both the $\sigma_{\mathrm{VM} \text {, max }}$ in the fillet-1 and pipe-1 rose up gradually with the nominal strain (Fig. 5 (a)). For all range of the nominal strain, 


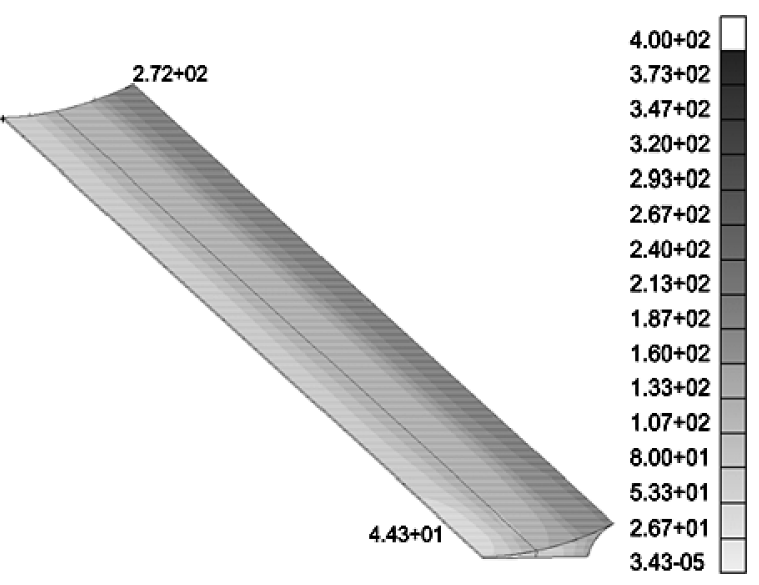

(a)

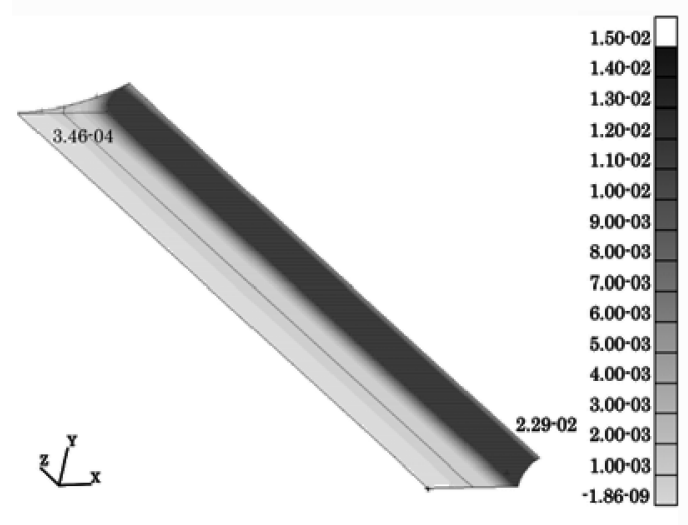

(c)
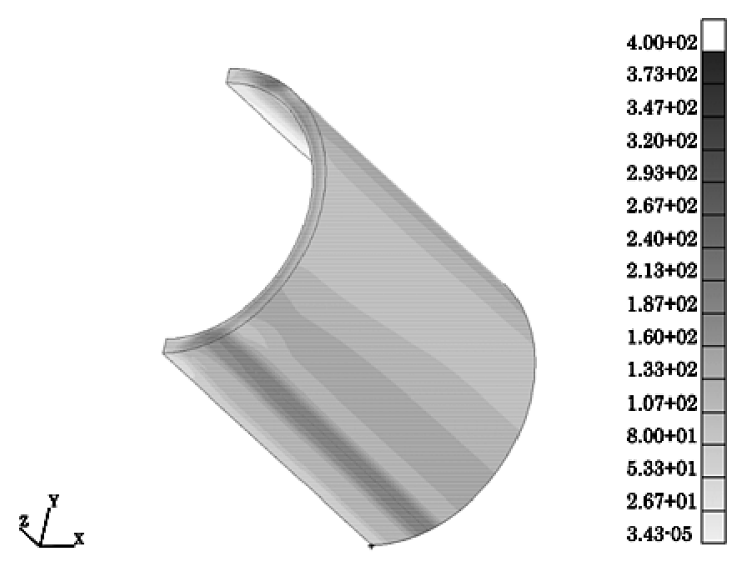

(b)
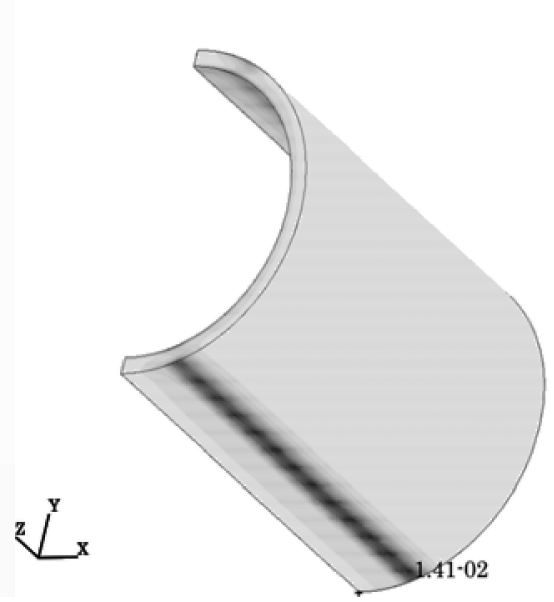

(d)

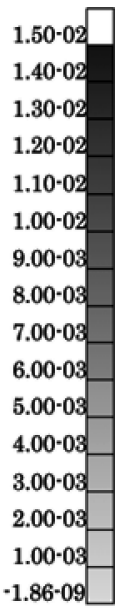

$1.86-09$

Fig. 4 Contours of the von Mises' equivalent stress and strain in the fillet- 1 and pipe- 1 for case \#1: the root gap is $0.05 \mathrm{~mm}$ and the apparent fillet width is $1.00 \mathrm{~mm}$. The applied displacement is $0.10 \mathrm{~mm}$. (a) von Mises' stress in the fillet-1 and (b) in the pipe-1. (c) von Mises' strain in the fillet-1 and (d) in the pipe-1

the $\sigma_{\mathrm{VM}, \max }$ in the pipe- 1 was higher than $\sigma_{\mathrm{VM}, \max }$ in the fillet-1. The $\varepsilon_{\mathrm{VM}, \max }$ values increased at exponential rate. The rate for the fillet-1 was higher than that for the pipe-1.

These tendencies were also found for other cases with different dimensions of the root gap and the apparent fillet width. When the apparent fillet width was increased (Fig. $5(\mathrm{~b})$ ), the $\sigma_{\mathrm{VM}, \max }$ in the fillet-1 was lowered. The $\varepsilon_{\mathrm{VM}, \text { max }}$ in the fillet-1, however, did not changed significantly. The $\sigma_{\mathrm{VM}, \max }$ and $\varepsilon_{\mathrm{VM}, \max }$ in the pipe-1 were left intact. When the root gap was widened but the apparent fillet width was kept the same (Fig. 5 (c)), the $\sigma_{\mathrm{VM} \text {, max }}$ in the fillet-1 was also lowered and other values showed the small difference. The geometric parameters' change might affect the stress state in the fillet-1 but in the pipe-1.

In the Fig. 5 (a), the $\sigma_{\mathrm{VM}, \max }$ and $\varepsilon_{\mathrm{VM}, \max }$ in the fillet1 were compared with the maximum stress, $\sigma_{\max }$, and rupture strain, $\varepsilon_{\max }$, of the BPd- $6+\mathrm{Ni}$ powder (Table 1). The $\varepsilon_{\mathrm{VM}, \max }$ did not reach to the $\varepsilon_{\max }$ within the displacement condition of the present calculation. But the $\sigma_{\mathrm{VM}, \max }$ ex- ceeded the $\sigma_{\max }$ of $264.0 \mathrm{MPa}$ at the nominal strain of $0.46 \%$, which were interpolated from the neighbor data. The $\sigma_{\mathrm{VM}, \max }$ and $\varepsilon_{\mathrm{VM}, \text { max }}$ in the pipe- 1 did not reach their limits. For all the other cases, only the $\sigma_{\mathrm{VM}, \max }$ in the fillet- 1 exceeded the $\sigma_{\max }$ of its material property. Therefore, the four-pipe-brazed specimen was expected to rupture at the touching point of the fillet and the pipe.

The nominal strain values at the expected rupture are summarized in Fig. 6 . When the apparent fillet width was set constant at relatively large value, 3.0 and $4.0 \mathrm{~mm}$ (Fig. 6(a)), the nominal rupture strain slightly increased with the increase in the root gap. For smaller apparent fillet width of 1.0 and $2.0 \mathrm{~mm}$, the clear tendency was not observed. To the contrary, if the root gap was constant (Fig. 6(b)), the nominal rupture strain almost linearly increased with the increase in the apparent fillet width.

\section{Discussions}

The results of the present research showed the nom- 


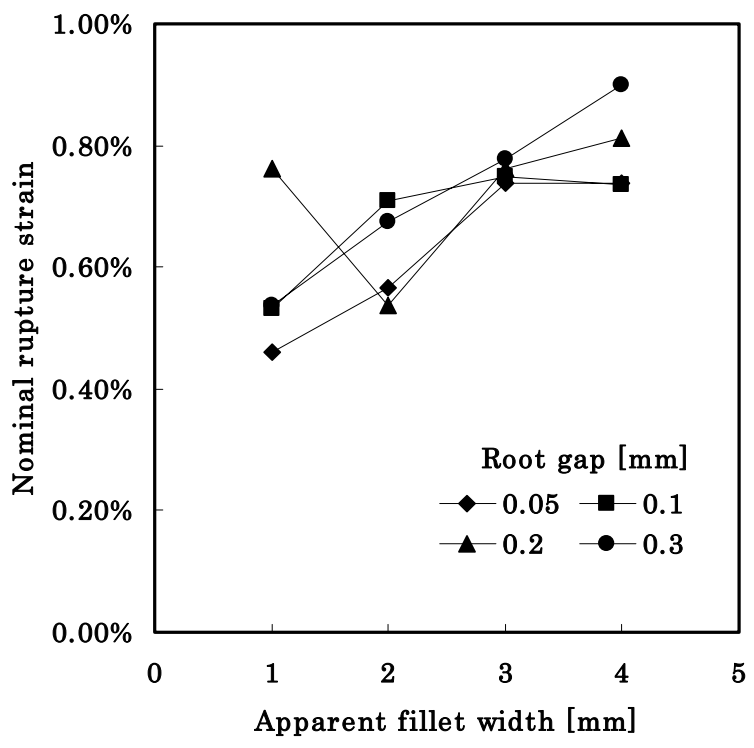

(a)

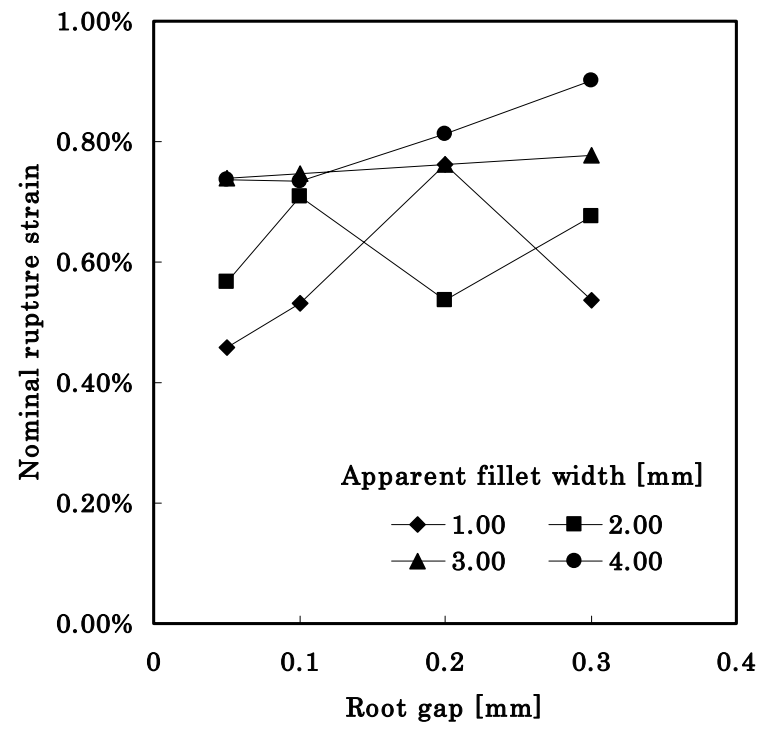

(b)

Fig. 5 Nominal rupture strain estimated from the von Mises' equivalent stress in the fillet-1

(a) vs. the apparent fillet width, and (b) vs. the root gap

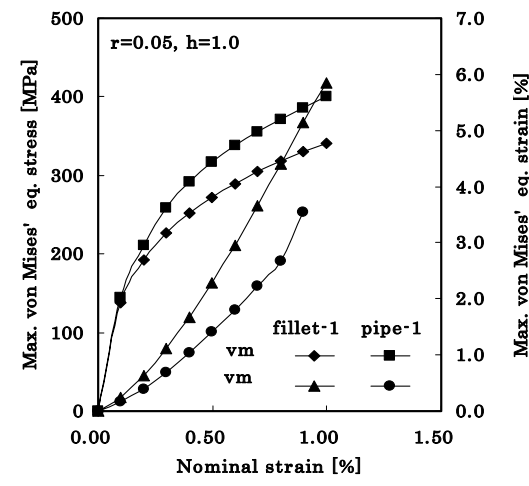

(a)

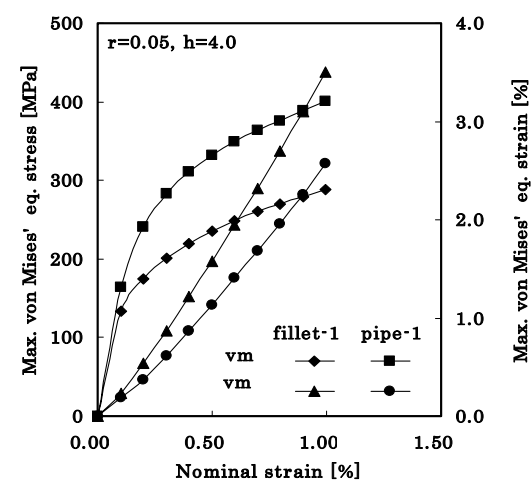

(b)

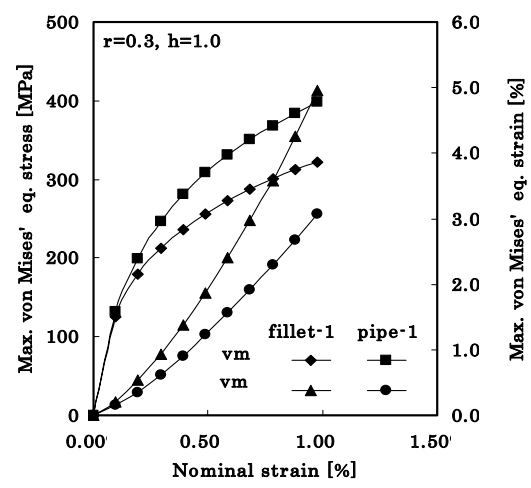

(c)

Fig. 6 Nominal strain vs. the maximum von Mises' stress and strain in the fillet-1 and pipe-

1. (a) Root gap, $r=0.05 \mathrm{~mm}$ and the apparent fillet width, $h=1.0 \mathrm{~mm}$ (case \#1), (b) $r=0.05, h=4.0$ (case \#4) and (c) $r=0.3, h=1.0$ (case \#13)

inal rupture strain, $\bar{\varepsilon}_{\max }$, increases with the apparent fillet width, $h$. The larger $h$ makes the fillet's size larger, and the stress state in the fillet part will be milder for the same applied displacement.

Adding to it, the stress concentration at the touching edge will vary with $h$. The equivalent curvature, $\bar{\rho}$, at the touching edge is $1 / R+1 / r$. It approximates to $1 / R+2 / h$, which is lead by the substitution of Eq. (1). Then the apparent fillet width, $h$, is in inverse proportional to the equivalent curvature. The plot of the equivalent radius of curvature, $1 / \bar{\rho}$, vs. $\bar{\varepsilon}_{\max }$ will be similar with Fig. 6 (a). For most of the root gap, the values of $\bar{\varepsilon}_{\text {max }}$ increase with $h$ and $1 / \bar{\rho}$. In the case of root gap of $0.2 \mathrm{~mm}$, its $\varepsilon_{\max }$ increases with $h$ over $2 \mathrm{~mm}$, but only for $1 \mathrm{~mm}$, its $\bar{\varepsilon}_{\text {max }}$ is high. In this case, the pinched-in part of the fillet is smaller compared with other cases, and the plastic deformation is con- sidered to be constrained and the brazing filler could endure higher load applied to the 4PB specimen than other case. The elongation of pipe was relatively larger than other case, and this resulted in the larger nominal rupture strain.

At the touching edge of the fillet to the pipe surface, the problem of stress singularity is also expected to arise. The stress singularity for the tip of the interface between the dissimilar materials must be considered. For such the multi-bonded wedge shape, the method to obtain the stress singularity around the wedges' tip has been proposed ${ }^{(9)}$. Unlike the wedge problem, the interface of the pipe and the brazing filler is the cylindrical surface, and the outline of the brazing filler is also the curved shape. The method could not be applied directly to this configuration. It must require the further analytical and numerical analyses. 
The root gap seem irrelevant to the nominal rupture strain. For the ordinal brazed joints, the narrower the root gap is, the brazing joint is tougher ${ }^{(10)}$. But, in this case, the pipes must be brazed with the line contact when the root gap gets smaller, the stress singularity would arise along the contact line. To avoid this effect, the 4PB might require a certain width of the root gap to maintain the joint strength.

The wider root gap is, however, feared to introduce the unexpected voids and to form the harmful intermetallic compounds by the reaction between the excessive brazing filler metal and the substrate.

For the combination of the palladium brazing filler metal to the stainless steel or the iron base heat resistant alloy, the high wettability was reported ${ }^{(11)}$. Besides it, the $\mathrm{Ni}$ powder stuffed with the brazing filler is considered to help the percolation of the molten brazing filler by the capillary. So the voids at the root gap might not be concerned.

According to the ternary phase diagram of $\mathrm{Ag}-\mathrm{Cu}-$ $\mathrm{Ni}^{(12)}$, the $\mathrm{Ni}$ is considered slightly to dissolve into the $\mathrm{Pd}$ filler. The small amount of $\mathrm{Ni}$ was measured to dissolve in the BPd- 6 brazing filler and the eutectic microstructure of $\mathrm{Ag}-\mathrm{Cu}-\mathrm{Pd}$ and $\mathrm{Cu}-\mathrm{Ni}-\mathrm{Pd}$ phases was observed ${ }^{(13)}$. The Ni$\mathrm{Cu}-\mathrm{Pd}$ phase is reported to be ductile phase ${ }^{(14)}$ and might not be the site of crack nucleation. Therefore, from the metallurgical view point, the root gap width might be irrelevant for the present combination of the brazing filler metal and the substrate.

In the present research, the lack of voids and the intermetallic compounds are involved into the material property of the brazing filler with Ni powder. The weak correlation of the root gap and the joint strength might be reasonable result. The actual 4PB joint strength, however, might show different relationship with the root gap. When the root gap is wider, the $\mathrm{Ni}$ powder reinforced brazing filler layer might not be uniform and the heterogeneity in the distribution of the Ni powder might lower the joint strength $^{(15)}$.

The size of fillet outside of the mating interface is said generally not relevant to the joint integrity or joint strength $^{(16),(17)}$. But the above analysis shows that the apparent fillet width is expected to large as possible to improve the strength of the brazed joint (Fig. 6(a)). The geometry of joint might make the 4PB unique case. From the view point of the special use of the rocketry, the large fillet, however, increases the weight of the NSA and consumes the cost of the noble metal brazing filler. So the apparent fillet width is preferred larger from the mechanical point of view, but is restricted by the design of the rocket engine and the factors other than engineering.

The in-process checking before the brazing process of the LE-7A's NSA claims the root gap and the apparent fillet width narrower than a certain value. The present results suggested the criteria for the inspection should be revised not only those root gap and the apparent fillet width.

\section{Conclusion}

For the four-pipes-brazed specimen model with various root gaps and the apparent fillet width, the numerical simulation using the finite element method with the elastic-plastic analysis is conducted. As results, the root gap has weak correlation with the joint strength, and the large apparent fillet width improves the joint strength.

\section{Acknowledgement}

A part of the present research was conducted under the support of the Japan Welding Engineers Society (JWES) and Japan Aerospace Exploration Agency (JAXA).

\section{References}

( 1 ) Huzel, D.K. and Huang, D.H., Modern Engineering for Design of Liquid-Propellant Rocket Engines (Progress in Astronautics and Aeronautics), (1992), p.431, AIAA.

(2) Fujiwara, C., Joining Technology for Aerospace crafts, Welding in the World, Vol.48 (2004), pp.249-254.

( 3 ) Schmitt, D.J., Novak, J.L., Starr, G.P.and Maslakowski, J.E., Real-Time Seam Tracking for Rocket Thrust Chamber Manufacturing, Proceedings-IEEE International Conference on Robotics and Automation, San Diego, CA, USA, (1994), pp.2261-2266.

(4) Ikeshoji, T.-T. and Suzumura, A., Evaluation of Strength of Side-Brazed-Pipe Joint, Research of Casting, Welding and Brazing Technologies for Space Crafts, Edited by Nishimoto, K., Japan Welding Engineering Society, Tokyo, (2002), p.4.8.2.

( 5 ) Modulus of Elasticity of Metals and Alloys (JSME Data book), Committee of The Modulus of Elasticity of Metals and Alloys, The Japan Society of Mechanical Engineers, Tokyo, (1980), p.159.

( 6 ) Harada, H., 4.9 Evaluation of Brazing Filler Metal at High Temperature, Research of Casting, Welding and Brazing Technologies for Space Crafts, Edited by Nishimoto, K., Japan Welding Engineering Society, Tokyo, (2002), p.4.9.1.

(7) Technical Data 1-Material Properties Table, http:// www.agc.co.jp/polycarbonate/pdf/tech/01.pdf, Aasahi Glass Company, (2005).

( 8 ) ABAQUS Theory Manual Ver.5.8, Hibbitt, Karlsson \& Sorensen, Inc. (1998), p.4.3.9-1.

( 9 ) Hwu, C., Omiya, M. and Kishimoto, K., A Key Matrix $\hat{N}$ for the Stress Singularity of the Anisotropic Elastic Composite Wedges, JSME Int. J., Ser. A, Vol.46, No.1 (2003), pp.40-50.

(10) Brandon, D. and Kaplan, W.D., Joining Process, (1997), p.226. John Wiley \& Sons Ltd., West Sussex.

(11) Schaefer, R.P., Flynn, J.E. and Doyle, J.R., Brazing Filler Metal Evaluation for an Aircraft Gas Turbine Engine Application, Welding Journal, Vol.50, No.9 (1971) pp.394s-400s.

(12) Villar, P., Prince, A. and Okamoto, H., Handbook of 
Ternary Alloy Phase Diagram, (1997), p.2303, ASM International.

(13) Ikeshoji, T., Watanabe, Y., Suzumura, A. and Yamazaki, T., Solubility and Dissolution Rate of Ni Base Alloy to Molten Ag-Cu-Pd Brazing Filler Metal, JSME Int. J., (2005), Accepted.

(14) Izui, H. and Suezawa, Y., Heat-Resisting Brazing of Stainless Steel SUS316L with PalladiumCopper Based Filler Metals, Yosetsu Gakkai Ronbunshu/Quarterly Journal of the Japan Welding Society, (in
Japanese), Vol.11, No.1 (1993), pp.36-42.

(15) Zou, J., Xu, R., Zhao, Q. and Chen, Z., Study on Vacuum Induction Brazing of SiCp/LY12 Composite Using $\mathrm{Al}-\mathrm{Cu}-\mathrm{Si}-\mathrm{Mg}$ Filler Metal, China Welding, (English Edition), Vol.12, No.2 (2003), pp.107-111.

(16) Jefferson, T.B., Designing for Better Brazements, Welding Engineer, Vol.59, No.4 (1974), pp.9-11.

(17) Kay, D., Fillets in Brazing: Good or Bad?, Welding Journal, Vol.82, No.10 (2003), pp.50-54. 